\title{
Construction Management: The management of the development, conservation and improvement of the built environment
}

\author{
Michael A Brown \\ Deputy Chief Executive, \\ The Chartered Institute of Building (CIOB)
}

DOI 10.5592/otmcj.2012.2.1

Invited Viewpoint

THE SEMANTICS OF PROFESSIONALISM IS A LITERAL MINEFIELD. UK Professions are established for the public benefit, in that they offer assurance of the skills and competences expected of a professional person, together with the application of ethical standards to their profession or trade. Yet the world of the professions is changing rapidly with new competences required to practice emerging technologies and new expectations of behaviours. The words we use do not keep pace.

\section{INTRODUCTION}

Denotation of the meaning given to words can be precise, but more often we interpret words to suit our own purposes, and the connotation given to words will suit our environment, geography and culture. Take 'engineering' for example; 'the branch of science and technology concerned with the design, building, and use of engines, machines, and structures'. Or is 'engineering' about 'ingenuity'. The Latin route of engineer is ingeniare, much closer in derivation to ingenuity. However, we have interpreted the word engine to be a physical thing, and so the public interpretation of 'engineer' can be as much about someone who fixes washing machines or cars, as it might be for a highly qualified professional engineer. The traditional German qualification of Diplom-Ingenieur leans directly toward 'ingenuity'.
Similarly with Architecture. The practice of architecture has become primarily about the planning and design of buildings, including the use of space and their appearance; meeting the clients requirements; and assessment of design quality. The derivation of the word 'architecture' goes back to the Greek, 'arkhitekton', meaning 'chief builder', primarily a mason or carpenter. Yet the modern day skills of 'building or construction', such as project management, cost and value engineering, and management of time, human resource and equipment management, and the knowledge and practice of creating on site a healthy and safe workplace may not be skills directly attributed to the 21st century architect.

Today the public and even informed clients may be confused about the skills and competences of otherwise recognised professionals, with questions- 
such as 'Who can identify the best procurement route to meet my needs?' 'Who can advise me if I am getting best value for my project?' 'Will my new building be truly sustainable and will I achieve my low carbon targets?' Will my building be delivered to time and budget?

The Chartered Institute of Building (CIOB), established in the UK but now with members world-wide, is continually challenged with the issue of titles and descriptors. 'Building' can be interpreted in a number of different ways, as a 'thing' or 'artifact' but also as the 'process' of building or business of construction: that is both noun and verb. It is also very broad in scope and can embrace the design process and the management of buildings in use.

However the trade or profession derived from the term 'building' is 'builder', which although had dignity under the Greek title 'Arkhitekton' or the traditional 'master builder', now has connotations of small-scale mediocracy and worse - the 'cowboy builder'. The CIOB's professional descriptor of Chartered Builder is often not perceived as equivalent to other professions, such as architecture or engineer, or accountants and medics, whose standard of professional formation and liability may not be dissimilar from the CIOBs. Yet in terms of scale, standards and responsibilities a professional builder may out score many other professionals.

During the 1980 s many university courses in 'Building' began to change their academic title to Construction Management. You will still find courses in the UK in 'Building Surveying', 'Historic Building Conservation' and 'Building Services Engineering', but not 'Building'. All 'Building' courses have the title 'Construction Management' or a derivative of it.

\section{The Profession of Construction Management}

The term Construction Management is not without its own connotations. Many people immediately think about a small- scale limited on-site role. This is far from the truth. People with the job titles 'Construction Manager' or 'Construction Director' tend to have high level roles in construction organisations, sometimes responsible directly to the construction client, and often with very large financial responsibilities.

Further there are other definitions of Construction Management. These are procurement models which offer a fee based service to the construction client focussing on delivery requirements to time and budget, enhancing design and construction quality, dispute avoidance, and so on.

The CIOB embarked on a project in 2008 to define the 'profession of construction management', irrespective of other definitions and uses of the terminology. Further, it was a requirement that the definition had international currency and Professor Li Shirong FCIOB, a Chinese academic and government officer, and then President of the $\mathrm{CIOB}$, was appointed to lead the work.

Construction Management (CM) is recognised throughout the world as one of a family of disciplines concerned with the 'Built Environment'. However, none of these disciplines has any monopoly of wisdom, nor any exclusive territory. The definition of the profession of Construction Management and its role in relation to the built environment is described in this paper, but as with other professional disciplines within the built environment, none can exist without the other.

An inclusive definition of Construction Management (CM) has been developed by the CIOB through a series of 'models', each of which recognises an aspect of the professionalism of Construction Managers. From these models, our definition has been developed.

\section{THE DEFINITION}

\section{ClOBs Footprint}

Management of the development, conservation and improvement of the built environment;
Since the $\mathrm{CIOB}$ was formed (as the Builders' Society in 1834), its mission has been concerned with the improvement of management of and in the construction industry. A huge body of evidence for this has been provided in the $\mathrm{CIOB}$ publication Building Visionaries: the Unsung Heroes (2009). Some of the biographies provided therein are of true master builders - people concerned to initiate and deliver projects, including buildings and infrastructure, which demonstrated excellence of both process and product. Some were pioneers of 'new construction' which was made possible through the developments of the Industrial Revolution, leading to the advent of the railways and the ability to transport construction materials over long distances, never before achievable. These men had extraordinary amounts of energy, organisational skill, and dedication to their workforce. Their reputation for integrity and dependability was impeccable. They were investors, developers and constructors; a tradition continued by many $\mathrm{CIOB}$ members whose role as developers and constructors continues to the present day.

Other CIOB members to the present have been reformers within the industry, concerned to develop and disseminate good practice, and to promote professionalism in $\mathrm{CM}$, working with government, clients and companies concerned to modernise and improve the way the industry works.

Others still have been concerned with the stewardship of the built environment - with its heritage, conservation, and its adaptation and improvement. Our footprint is now visible in many different parts of the world, notably, as the CIOB publication Building Modern China (2009) demonstrates in that most rapidly growing part of the world construction industry. The $\mathrm{CIOB}$ footprint is large and ubiquitous, its edges are at times fuzzy, but it is clearly recognised as that we define as Construction Management. 


\section{A Hierarchy of Systems}

... exercised at a variety of levels from the site and project, through the corporate organisations of the industry and its clients, to society as a whole;

It is part of most international definitions of construction that it is concerned with physical structures. Management of construction at site level has been and remains a vital part of the CIOB's mission and of any definition of Construction Management. It is equally clear that site management is but one level in what may be described as a hierarchy of systems. What happens on site is influenced by decisions taken in the initiation, development, planning, pricing and procurement of projects. Projects, increasingly, are linked together into programmes - programme management.

In CIOB's Construction Manager of the Year Awards (initiated in 1979), the term construction manager embraces site and project management, and, while it is the performance of the individual manager that is recognised, it is clear the quality of the construction firms of which those managers are part is a major determinant of success.

Project management, in the sense of the integrated management of entire projects on behalf of a client, is a key aspect of Construction Management as it is defined here. The CIOB has exercised leadership in the codification of good practice in project management (The Code of Practice for Project Management for Construction and Development, first published in 1992, now in its fourth edition).

Organisations of various kinds are intimately involved in every project, so that the success of the project as temporary organisation is affected by the resources and effectiveness of the corporate organisations out of which it springs. Institutions of the construction industry and government also influence industry performance, through research, information dissemination, training and the promotion of safe working practices.
Finally society as a whole is a stakeholder in the industry. Quality of life, in its economic, social, cultural and environmental dimensions, depends upon the existence of an efficient and innovative construction industry, especially in the light of a low carbon future.

\section{The Construction Value System ...embracing the entire construction value stream from inception to recy- cling, and focussing upon a commit- ment to sustainable construction;}

The construction value stream begins with a perceived need for a new or improved building or structure, and leading to investigation, design, production, commissioning, facility management, maintenance, adaptation, conservation, restoration, dismantling and recycling. $\mathrm{CIOB}$ members, throughout the Institute's history, have operated at all of these stages, in partnership with other built environment professionals.

Clients have recognised, and many official reports have exhorted, that the involvement of construction managers in the initiation of projects, and in design management aimed at integration of design and production, is vital to project success. Early engagement with the project enables the construction manager to deliver a more sustainable product, through the elimination of waste, the re-use of demolition materials, more efficient construction practices, off-site fabrication, and so on.

The future role of the construction industries, and therefore of CM, will increasingly concern the stewardship of the built environment. CIOB members across the globe share a desire to realise the ideal of sustainable construction, whether a project is for new-build, or for refurbishment and adaptation.

What is clear is that CM as we are defining it must reflect the entire value stream throughout which $\mathrm{CIOB}$ members operate - whether their work is in construction companies, consultant practice, client organisations, govern- ment or elsewhere. This spectrum includes facilities management, given the increasing importance of the stewardship and improvement of existing built assets in the work of the professional construction manager.

\section{Specialist Services}

\section{... incorporating a wide range of spe- cialist services;}

Over the lifespan of the $\mathrm{CIOB}$, an increasing variety of specialist roles has developed within the construction companies where historically the majority of CIOB members have worked. Bodies of knowledge have been developed around these roles and the CIOB has played a major part in the definition of good practice and the development of research, education and training.

One such example is cost prediction, where the CIOB Code of Estimating Practice (now in its seventh edition) provides an industry standard. Equally, CIOB members have found that their expertise allows them to offer specialist services in consultant practice, for example in the management of complete projects on behalf of clients - where again a CIOB publication has provided an authoritative and widely accepted definition of good practice (the Code of Practice for Project Management for Construction and Development, first published in 1992, now in its fourth edition).

Many other fields of specialist practice have arisen. Some have drawn naturally upon the expertise CIOB members have acquired in their training, and which they have subsequently developed to expert level - for example in building pathology, health and safety management, building standards and control or dispute resolution. In other cases, people trained in functional management fields (for example HR management or purchasing) have come to work in construction and wanted to become part of the construction culture and to deepen their expertise within it. The $\mathrm{CIOB}$ has embraced the professionalism of such people through its non-cognate 
route to membership, just as it has been able to provide an additional professional home for those trained in other built environment disciplines, who have chosen to identify with our CM ethos.

\section{Our Value System}

... guided by a system of values demonstrating responsibility to humanity and to the future of our planet;

Over its life the CIOB has developed a system of values which flows naturally from the work of our members. It is truly a 'people business' because virtually every construction project is a prototype, requiring the creation of a team, and sensitive attention to complex human interactions in conditions of partial uncertainty. More importantly, construction is a business for people, for communities, for societies in a way that makes it different from any manufacturing industry. Buildings frequently outlive people; they help to shape societies, and they reflect society and culture.

It is clear from the published histories of the CIOB and its members that this concern for human values has consistently transcended more instrumental concerns for construction technology and management technique. There is however, no room for complacency. Construction is also an industry which, worldwide, has appeared prone to corruption - for reasons related, inter alia, to the attractive value of developed land, and the nature of contracting processes, and the exchange of large sums of money. It is also a global industry, where the workforce has often been disgracefully neglected, where women have been inadequately represented, and where discrimination against ethnic and other minorities has been too often unchecked. Whilst all built environment professionals have a role in curbing these excesses, the professional construction manager is in a position to bring about real change.

A system of values related to concern for the environment in all its aspects (carbon reduction, biodiversity, local communities), and for the industry's own workforce, is a vital aspect of what the CM discipline must stand for; indeed it is the paramount reason why construction as industrial practice must be shaped and guided by CM as a discipline.

\section{CM as an Academic Discipline Contributions \\ ... informed, supported and chal- lenged by an independent academic discipline.}

Within the construction management educational community there exists a lively, international and liberal academic discipline. The academic discipline is not necessarily coterminous with CM as a field of professional practice; it is right that it should both probe critically within professional and industrial practice, extend beyond it, and stand outside it as an independent observer. It is right too that it should reflect upon not only on how things are now, but how they might be: in a proper sense, every academic discipline must be idealistic.

The development of knowledge and understanding is important its own right - and that must be true of CM as of any other discipline, however it supports the development of professional competence and practice. The fact that it springs out of an industry does not make it subservient to industry. The existence of a lively $C M$ research culture has, throughout the world, informed higher education courses, producing graduates who are intellectually able to challenge the status quo and to move the practice of CM forward.

Development of the discipline must continue, and be intensified if the practice of $C M$ is to meet the challenges indicated earlier. Our ability to make accurate predictions about industrial performance is limited by available research, and by what are still inadequate links between practice and academe.

\section{Construction Management: our Definition}

The management of the development, conservation and improvement of the built environment;

exercised at a variety of levels from the site and project, through the corporate organisations of the industry and its clients, to society as a whole;

$\checkmark$ embracing the entire construction value stream from inception to recycling, and focussing upon a commitment to sustainable construction;

incorporating a wide range of specialist services;

guided by a system of values demonstrating responsibility to humanity and to the future of our planet;

$\checkmark$ informed, supported and challenged by an independent academic discipline.

\section{References}

This paper includes extracts from the 'CIOB's Professionalism:

An inclusive definition of Construction Management', by Professor John Bale FCIOB and commissioned by Professor Li Shirong FCIOB, then President of the CIOB, ISBN Number: 978-1-85380-501-1, Copyright (C) The Chartered Institute of Building 2010 